\title{
André de Resende e Jerónimo de Azambuja: Da interpretação dos textos mosaicos
}

\author{
Virgínia Soares Pereira \\ Universidade do Minho
}

"Por isso quis dar disso testemunho perante Vossa Alteza"

André de Resende

O presente estudo centra-se no comentário, edição e tradução de uma carta de André de Resende dirigida, em 1557, ao Cardeal-Infante D. Henrique, em jeito de prefácio ao Levítico, comentado por Jerónimo de Azambuja. Sem ser uma peça eloquente, mas atendendo ao destinatário, a carta não deixa de revelar a personalidade de um humanista de grande prestígio que em todas as circunstâncias percebeu a proximidade entre eloquência e política.

\section{Breve introdução}

Na carta em referência, André de Resende, teólogo dominicano, exalta perante o Cardeal o trabalho exegético de Azambuja, igualmente teólogo dominicano, e põe o acento tónico na dificuldade de interpretação do texto hebraico, que dificilmente pode ser lido e compreendido sem o auxílio de comentários. A carta, em rigor, nem é nuncupatória nem é prefatória, parecendo antes um misto das duas modalidades. Qual a sua real intenção?

Jerónimo de Azambuja (?-1563), também conhecido como Oleastro (forma latinizada de Azambuja), ${ }^{1}$ teólogo e inquisidor, é considerado um dos exegetas portugueses mais insignes de todos os tempos. ${ }^{2}$ Detentor de um notável conhecimento da língua hebraica, filólogo e comentador escriturístico de alta craveira, Azambuja já no

\footnotetext{
${ }^{1}$ Natural de Alenquer, segundo A. A. Martins Marques (1964-66: 193), que considera que Azambuja é apelido de família e não indica a sua terra natal. Por seu turno, M. Augusto Rodrigues (1973: 17-18) considera-o natural de Azambuja.

2 Palavras de Manuel Augusto Rodrigues (1977: 25). Veja-se, do mesmo autor (1974: 16-19), uma súmula da vida de Azambuja e bibliografia.
} 
seu tempo viu reconhecido o seu valor, a avaliar pelos testemunhos que Barbosa Machado regista no respectivo verbete da Bibliotheca Lusitana. Fez a sua formação em Portugal (frequentou em Lisboa, em 1525, o Colégio Universitário de S. Tomás) e em Lovaina (em cuja universidade se encontra no ano de 1536). Regressado à sua terra natal, e depois de ensinar em Lisboa e em Évora, foi escolhido por D. João III, em 1545, para participar no Concílio de Trento. Será pouco tempo depois, ainda antes de o Concílio terminar, nomeado deputado da Inquisição, "com o especial encargo da censura dos livros". 3 A partir de 2 de Setembro de 1552, é-lhe confiado o Tribunal do Santo Ofício, em Évora e em Outubro de 1555 passa a exercer o cargo em Lisboa, mantendo-se nele até 1560 , na sequência da sua eleição como Prior Provincial dos Dominicanos. Do conjunto da sua produção exegética, destacam-se os Commentaria ad Mosi Pentateuchum e os In Isaiam prophetam Commentarii.

Por sua vez, André de Resende (1500-1573), um dos grandes vultos intelectuais da Évora quinhentista, notabilizou-se como prestigiado humanista, dividindo o seu tempo entre as actividades de teólogo, pregador dos cardeais D. Afonso e D. Henrique, professor de príncipes e nobres, arqueólogo, historiador, biógrafo, gramático, poeta... Formou-se em Teologia Sagrada, mas sempre tentou conciliar os estudos bíblicos com os estudos clássicos, na esteira dos ensinamentos de Erasmo, defendendo a ideia de que a verdade cristã não é incompatível com a elegância clássica.

Com tais curricula, importa perceber em que momento(s) é que os caminhos e saberes de um e de outro se cruzaram, a ponto de Resende ser chamado a prefaciar um Comentário de Azambuja a um texto hebraico.

Segundo revela o próprio Resende na referida carta ao Cardeal, os primeiros contactos de André de Resende e Jerónimo de Azambuja datavam do período da sua adolescência. Apesar do carácter vago das suas palavras, que não permitem precisar datas, supõe-se que terão sido companheiros de estudo no mosteiro dominicano, talvez em Évora, antes de, em 1513, Resende rumar à Universidade de Alcalá de Henares. Mais tarde, regressados um e outro a Portugal, depois de concluída a sua formação em terras estrangeiras, tiveram ocasião de conviver em Évora (terra natal de Resende e área de acção de Azambuja como inquisidor, de 1552 até 1555) e Lisboa (lembre-se que

\footnotetext{
${ }^{3}$ A. A. Martins Marques (1964-1966:196); vd. também pp. 201-203, nas quais fala da importância e originalidade de Oleastro na organização do Índice de livros de 1551, apesar de Azambuja se ter porventura inspirado no Índex elaborado pela Universidade de Lovaina em 1550, segundo Raul Rego (1982: 41-46). No exercício das suas funções de deputado da Inquisição de Lisboa, preocupou-se essencialmente com os livros estrangeiros que entravam em Portugal, consciente de que poderiam atentar contra a integridade e ortodoxia da doutrina católica.
} 
neste ano passou a exercer o cargo na diocese de Lisboa e Resende, que preferia Évora, apenas em serviço do Cardeal se deslocava à capital do reino), em suma, nas cidades onde, além de Coimbra, se desenrolava o essencial da actividade política, religiosa e intelectual do país. ${ }^{4}$

Na qualidade de teólogo e professor de Sagrada Teologia, Resende teve de se dedicar ao estudo da língua hebraica, talvez em Lovaina, no Colégio Trilingue. Foi aqui que, segundo C. Michaëlis de Vasconcelos, Resende estudou rudimentos de Hebraico e cultivou as línguas clássicas, travando conhecimento e convivendo em estreita amizade com os mestres mais prestigiados, como o Campense (que foi mestre de Hebraico no Colégio Trilingue de Lovaina, de 1520 a 1531), Rogério Réscio, Conrado Goclénio e Nicolau Clenardo, exercitando-se com este na língua hebraica "um pouco de tempo" e trazendo-o mais tarde a ensinar em Portugal. ${ }^{5} \mathrm{Na}$ verdade, Clenardo ensinou Hebraico e Grego em Lovaina e, entre outras obras, é autor de uma Tabula in Grammaticam Hebraeam. $^{6}$

O conhecimento da língua hebraica por parte de Resende não se faz sentir na sua obra, a não ser escassamente. Assim, no final do Livro IV do Aegidius Scallabitanus, falando da etimologia de hursacrum (usagre) e apoiando-se no saber dos médicos de origem judaica, afirma que se trata de um composto híbrido formado de uma palavra hebraica (hur, que corresponderia ao grego pyr e equivaleria ao latim ignis, 'fogo') e do lexema latino sacrum ('sagrado'). ${ }^{7}$

No registo meramente linguístico, esta é uma das poucas abonações da língua hebraica em Resende. Mas quando nos referimos ao conhecimento dos textos bíblicos, nesse caso a preparação de Resende é indiscutível e reflecte-se em várias obras. Lembre-se o primeiro sermão que pregou no Sínodo de Évora, em 1534, no tempo do Cardeal-Infante D. Afonso. Nesta elegante peça de oratória sacra, em latim, o humanista estrutura e desenvolve o tema da necessidade de morigeração dos membros da Igreja

\footnotetext{
${ }^{4}$ Sobre Évora e a sua importância política, social, intelectual e artística, pois era a segunda cidade do país, no séc. XVI, veja-se Luís de Matos (1976).

${ }^{5}$ Vd. M. Cerejeira (1974 -1975, II: 96). É o próprio Resende que, num dos seus frequentes e por vezes inesperados registos autobiográficos, como o que surge no cap. X da Vida do Infante D. Duarte, refere estes dados.

${ }^{6}$ M. Augusto Rodrigues (1984: 128). Este estudioso informa (p. 133) que Clenardo tinha a intenção, manifestada em carta a Fr. Brás de Braga, de estabelecer o ensino da língua sagrada nos Claustros de Santa Cruz de Coimbra, em 1537. Este mesmo autor (1973: 12), referindo-se ao ensino do hebraico no Colégio das Artes, em Coimbra, lembra que "não era permitido ensinar hebraico e outras disciplinas em escolas privadas ou públicas, salvo nas Escola Gerais e nos conventos da cidade." Daqui em diante, o interesse pelo hebraico irá redobrar, dada a necessidade de os católicos responderem com rigor às posições dos reformadores e heréticos.

${ }^{7}$ Vd. texto, tradução e notas em André de Resende (2000: 604-605 e 695, n. 28).
} 
com base na frase do profeta Joel $(2,15-16)$ que diz: Vocate caelum, congregate populum, sanctificate ecclesiam, coadunate senes. A fim de sustentar a sua argumentação, e bem assim as duras críticas que dirige ao estado da Igreja, apoia-se em vários passos bíblicos, nomeadamente do Velho Testamento, comentando em especial o passo de Ezequiel (16, 1-63), "a famosa e belíssima alegoria da infidelidade de Jerusalém, comparada com uma esposa ingrata e adúltera", no dizer de Sebastião Tavares de Pinho. ${ }^{8}$ Mais tarde, nas famosas adnotationes ao poema Vincentius, leuita et martyr, 1545, encontram-se, em jeito de justificação de expressões do seu poema, referidos e comentados vários episódios bíblicos. ${ }^{9}$

Um segundo sermão, proferido também em Évora no sínodo diocesano de 1565, trata o tema da santificação dos eclesiásticos partindo do Salmo 99, vers. 5: Congregati illi sanctos eius, qui ordinant testamentum eius, super sacrificia. Neste sermão, que constantemente apela a citações veterotestamentárias, nomeadamente dos livros do Pentateuco, são duramente atacados Lutero e outros heréticos por pretenderem, sem autoridade, "non somente inquirir, mas condemnar ho que fixo e firme stava."10 Distando entre si duas décadas, estes sermões, elegantes e fortes, constituem o que de mais relevante Resende compôs na área da Sagrada Escritura.

Mais saberíamos sobre o interesse de Resende pelos textos bíblicos, se fosse possível conhecer o recheio da sua biblioteca pessoal, que seria grande. Mas os dados de que dispomos são escassos. Um dos mais importantes colhe-se no seu testamento, começado a exarar por volta de 1570 , no qual declara, a dado passo: "Leixo a minha livraria ao moesteiro de Sam Domingos, convem a saber, a que pertence a Teologia, Sagrada Escritura, Filosofia, Historia ecclesiastica, Exposição de Autores, e outros livros, que elles julgarem, que lhe sam necessários (...).” E mais adiante, referindo em especial certos livros: "Particularmente leixo o meu livro grego Ioane Climacho, de Ascensu in Caelum, e huma Biblia hebraica Aldina da impressam de Aldo ao Collegio de Ihesu, e assim a Biblia grega toda." 11 As duas obras referenciadas em especial destaque, a Bíblia Hebraica e a Bíblia Grega, são uma prova claríssima do interesse de Resende pelos estudos bíblicos e, em particular, pelo texto hebraico da Bíblia. Com a

\footnotetext{
${ }^{8}$ Para o conhecimento deste importante sermão, veja-se Isaías da Rosa Pereira (1971: 171-232) e Sebastião Tavares de Pinho (2006: 153-182), que considera o comentário de Resende à alegoria de Ezequiel uma das críticas mais acerbas que foi possível fazer aos desvios da Igreja e à degradação dos seus membros.

${ }^{9} \mathrm{Vd}$. André de Resende (1981: 72-81).

${ }^{10}$ Para o estudo deste sermão, vd. Isaías da Rosa Pereira (1991-1992: 190-201).

${ }^{11}$ Transcrito de F. Leitão Ferreira (1914: 225-226).
} 
sua veia filológica, não terá deixado de fazer um estudo comparativo dos textos do Antigo Testamento e suas traduções, como fez Azambuja.

\section{A obra de Azambuja}

Da sua obra de exegeta chegaram até nós os Commentaria in Mosi Pentateuchum e os In Isaiam prophetam Commentarii. São duas obras de grande fôlego, densamente filológicas, por um lado, e de orientação moral, por outro. De facto, é uma constante do seu trabalho de exegese apresentar, para cada capítulo, o comentário ad litteram (isto é, o comentário que visa o sentido literal) seguido do comentário ad mores (o comentário que procura apreender o sentido espiritual). Na edição de 1557, esta dupla modalidade de comentário vem assim titulada (exemplo do cap. 30): Capitis XXX. Iuxta literam annotationes e Capitis XXX. Ad morum compositionem annotata.

A quem não esteja familiarizado com a natureza e os pressupostos destes Comentários, importa referir que os princípios que nortearam Azambuja no seu imenso trabalho de exegese se encontram registados nos dezasseis cânones que ele mesmo elaborou e que figuram a encabeçar o texto desses Comentários. ${ }^{12}$ São várias as ideias directrizes expendidas. Assim, considerava que só o conhecimento das duas línguas do Velho Testamento, o Hebraico e o Grego, permitiria o acesso aos textos bíblicos. São poucos, contudo, os que sabem Hebraico. Nesse caso, aconselha-os a que se sirvam, como ele mesmo fez, da tradução para latim de Sanctes Pagnino. ${ }^{13}$ Mas está ciente da novidade (perigosa) deste conselho. Lembra, por isso, a quem possa estranhar que não tenha aconselhado a tradução latina conhecida por Vulgata, oficialmente sancionada pela Igreja de Roma, que esta tradução não está isenta de erros, um facto que o próprio S. Jerónimo, autor da Vulgata, reconhecia. ${ }^{14}$ Sem temer o escândalo que adviria de

\footnotetext{
${ }^{12}$ São conhecidos com o título de Hebraismi et Canones pro intellectu Sacrae Scripturae e, tanto quanto se sabe, nunca tiveram edição separada. Além das orientações necessárias a quem queira penetrar nos arcanos do texto bíblico, Azambuja elaborou listas de palavras e expressões que são próprias do idioma sagrado (os chamados hebraísmos).

13 Sanctes Pagnino (1470-1541?), O.P., foi um dos mais célebres hebraístas do seu tempo. Publicou em 1528, em Lyon, a obra Vtriusque instrumenti noua translatio, uma tradução da Bíblia a partir dos textos originais, que constituiu uma verdadeira revolução na sua época. A sua tradução do Antigo Testamento foi, desde S. Jerónimo, a primeira a ser feita directamente do texto hebraico. Levou vinte e dois anos a realizar o trabalho e a sua divisão em capítulos e versículos permanece inalterada até aos nossos tempos. Pela mesma altura publicou em Lyon o Thesaurus linguae sanctae, "um léxico hebraico bastante desenvolvido", segundo informação colhida em Manuel Augusto Rodrigues (1984: 128).

${ }^{14}$ É no Prefácio ao leitor, que antecede os Comentários, que Azambuja refere este dado, acrescentando que não pretende denegrir S. Jerónimo, mas que o considera um homem, não um profeta. São estas as palavras: Quae non in eum finem adducimus, ut uirum sanctum traducamus, sed ut sententiamus eum non Prophetam, sed hominem. Como lembra Manuel Augusto Rodrigues (1974: 17), Azambuja chegou
} 
emendar a Vulgata, o comentador propunha-se uma exegese secundum hebraicam ueritatem. Pelas mesmas razões, não mostrava interesse em citar a opinião dos padres da Igreja, preferindo citar as próprias Escrituras Sagradas, exactamente por considerar que só o texto original da Escritura é inspirado. ${ }^{15}$ Em todo o caso, em muitos passos põe a sua interpretação à disposição do juízo crítico dos outros, afirmando que podem discordar dela e ater-se à versão tradicional.

Esta sua preocupação era própria de quem tivera uma sólida formação humanística e conhecia a verdadeira importância do estudo aprofundado dos textos sagrados para alcançar o seu cabal entendimento. Lorenzo Valla, Lutero e Melâncton advogavam a necessidade de tomar em mãos os textos bíblicos originais para aí se encontrar a palavra de Deus. Também Erasmo (na Ratio perueniendi ad ueram Theologiam) insistia neste ponto. Opunham-se todos à exegese tradicional e escolástica, bem como ao texto da Vulgata, que na Idade Média era, por assim dizer, a Bíblia oficial da Igreja latina. Voltará a sê-lo depois do Concílio de Trento, que em 1546 fixou a versão jeronimita como o texto oficial da Igreja. ${ }^{16}$

Defender, como Azambuja faz, ideias tão inovadoras e ousadas no seu tempo, aplicando aos textos sagrados o método de que se serviam os grandes humanistas, só terá sido possível pelo facto de ele mesmo ser inquisidor e ter a protecção do Cardeal, Inquisidor-Mor. Os seus Comentários revelam-se de uma grande riqueza filológica e hermenêutica e foram, logo no seu tempo, muito apreciados pelos especialistas. Mas a sua independência como exegeta bíblico, que nem todos compreenderam e alguns censuraram, terá contribuído para que, apesar de membro destacado da Inquisição, tenha visto a sua obra incluída no Index de 1624 . Houve mesmo quem sugerisse que o facto de assinar com o termo latino Oleaster (Oleastro) ${ }^{17}$ poderia ter sido uma forma de "iludir" a autoria da obra.

\section{A carta de André de Resende ao Cardeal-Infante D. Henrique}

\footnotetext{
mesmo a propor ao papa Paulo IV que ordenasse a correcção da Vulgata tendo em atenção os textos originais.

${ }^{15}$ Para um conhecimento inicial dos Commentaria de Azambuja e do seu método exegético, veja-se A. A. Martins Marques (1966: 123-150).

${ }^{16}$ Vd. M. Augusto Rodrigues (1984: 112).

${ }^{17}$ Oleaster,-tri, ‘(a)zambujeiro'.
} 
A carta elogiosa de André de Resende data de 15 de Julho de $1557 .{ }^{18} \mathrm{O}$ rei D. João III falecera a 11 de Junho de 1557, em Lisboa. De acordo com informação do próprio, Resende fora chamado ao serviço do cardeal D. Henrique e encontrava-se em Lisboa no exercício de incumbências cuja natureza não é revelada. Neste entretanto, na tentativa de se distrair um pouco do ambiente opressivo que se vivia no país, na sequência da morte do rei - que partia sem deixar qualquer filho vivo, encontrando-se a sua sucessão entregue à regência da Rainha D. Catarina, avó do príncipe Sebastião, de três anos apenas ${ }^{19}$-, Resende visitava regularmente Fr. Jerónimo de Azambuja - então inquisidor em Lisboa -, que aproveitou o ensejo para lhe dar a conhecer os Comentários ao Pentateuco, em que andava a trabalhar. Encantado com a qualidade da obra e com a sua extrema utilidade, em particular para aqueles que, sabendo um pouco de hebraico, sentiam dificuldades em entender o texto e o sentido das Sagradas Escrituras - era, de resto, o seu próprio caso, como confessa -, Resende decidiu apresentar a obra ao Cardeal D. Henrique. Para tal, escreveu a carta que apresentaremos no final, em texto latino e tradução. ${ }^{20}$

Três motivos moveram Resende a escrever a carta: 1. Fazer o elogio do amigo, encarecendo aas suas qualidades naturais e a sua erudição. O humanista eborense admira nele a extraordinária cultura bíblica e o domínio perfeito da língua hebraica. E tinha razão no elogio. Segundo M. Augusto Rodrigues, Azambuja foi um "exímio comentador escriturístico e filólogo consumado" e contribuiu com o seu denodado esforço exegético para uma maior inteligência do texto sagrado. ${ }^{21}$ Além deste motivo, outros dois: 2. Uma convivência de longa data, desde os tempos da adolescência, no convento dominicano de Évora. Finalmente (retoricamente last, but not least): 3. O facto de Azambuja desempenhar, a convite do Cardeal, as funções de inquisidor, um

\footnotetext{
${ }^{18}$ Esta carta, entre o prefácio e a dedicatória, saiu impressa em Lisboa, a anteceder os Commentaria in Leuiticum, editados em Lisboa em 1557, na Oficina de João Blávio. Neste mesmo mês de Julho e na mesma tipografia que imprimiu os Commentaria in Leuiticum prefaciados por Resende, este humanista imprimiu igualmente o poema à morte de D. João III, que se apresenta com o seguinte título: L. Andreae Resendii in obitum D. Joannis III. Lusitaniae Regis, Conquestio. Permissu et auctoritate Reuerendissimorum Inquisitorum. Olisipone, apud Joannem Blauium Typographum Regium, mense Julio. M. D. LVII. A respeito deste poema, veja-se a notícia de F. Leitão Ferreira (1910: 357-358) e as respectivas notas de A. Braancamp Freire.

${ }^{19} \mathrm{O}$ facto de D. João III e D. Catarina terem visto morrer, ano após ano, todos os seus filhos enlutou profundamente a Casa Real e o país e marcou um período de grande tristeza nacional. A morte do rei veio adensar esse clima e lançar a incerteza quanto ao futuro do país, mergulhado numa crise sem precedentes. A carta de Resende alude a esse sentimento geral de perda e de luto.

20 Não conheço qualquer tradução desta carta. M. Augusto Rodrigues (1977: 29-31) dá a conhecer excertos dela, mas não os traduz, fazendo deles um breve resumo e comentários.

${ }^{21}$ M. Augusto Rodrigues (1977: 26).
} 
cargo "tão importante quanto perigoso". E assim, nestes três motivos, eram apregoadas três qualidades: as do talento natural e erudição, as da velha amizade e a institucional...

A ilustrar a extraordinária competência de Azambuja na interpretação do texto bíblico, Resende chama particular atenção para o passo Gen. 30, que tem que ver com a história de Jacob e Labão - aquele episódio bíblico que seria imortalizado entre nós pelo famoso soneto camoniano que começa: Sete anos de pastor Jacob servia. Nessa história bíblica, Jacob é em várias ocasiões ludibriado por Labão. A fim de encarecer as competências exegéticas do amigo, Resende fala das dificuldades que enfrentou para dar sentido à astúcia de que Labão, patriarca, reiteradamente usou para com Jacob. Mas não é explícito quanto à natureza dessas dificuldades. E a leitura do comentário de Azambuja não auxilia muito à compreensão da afirmação de Resende. Talvez se possa depreender das suas palavras que a dificuldade de interpretação residiria, não no sentido literal, alcançável mediante uma rigorosa análise filológica, mas sim na interpretação (e sentido moral) a dar ao conhecido episódio.

No comentário de Azambuja ao episódio, figuram inúmeras observações filológicas e hermenêuticas, relativamente às quais admite que o leitor possa não estar de acordo com a sua leitura e preferir a leitura tradicional. Diz, dirigindo-se ao leitor em pleno comentário do referido capítulo 30: Parce prudens lector si quod intelligo, expressi: quoniam non prohibeo communem interpretationem. Confer quae diximus, et si probaueris, tene, sin minus, reiice. Dominus ipse nouit quid laboris pertulerimus in eruendis ueris dictionum significationibus. ${ }^{22}$ Isto é, o próprio comentador confessa que a sua interpretação não é a tradicional. Só Deus sabe, confessa, quanto esforço lhe exigiu tentar descobrir o verdadeiro sentido das palavras! O comentário de Resende parece glosar este passo.

Em muitos outros passos Azambuja não esconde haver no texto bíblico trechos de difícil interpretação, que nem as conjecturas ajudam a resolver. Para dar mais um ou dois exemplos, atente-se no comentário relativo ao passo bíblico que fala do sinal posto por Deus a Caim. Diz o Gen. 4: Et posuit Dominus ipsi Cain signum, ut non percuteret illum omnis inueniens eum. ${ }^{23}$

Comentando o sentido deste sinal, Azambuja escreve: Non solum, ut non occiderent eum, sed etiam ne percuteretur. Quod signum hoc fuerit, textus non explicat,

\footnotetext{
22 "Desculpa, avisado leitor, se exprimi o que penso, pois não impeço a interpretação comum. Analisa o que disse e, se estiveres de acordo, toma-a para ti; se não, deita-a fora. O próprio Senhor sabe quanto trabalho suportei na descoberta do verdadeiro sentido das palavras."

23 "E pôs o Senhor um sinal ao próprio Caim, para que todo aquele que o encontrasse o não ferisse."
} 
neque est aliqua coniectura ad hoc sciendum, neque libenter in sacris literis historias fingo. $^{24}$

Há que relevar, neste caso, a isenção de quem, atendo-se ao sentido literal, nada mais pode acrescentar. De natureza bem diferente é o comentário relativo às palavras (que constam do referido capítulo 30 do Génesis): Iratus est furor Iaacob in Rachel (“Jacob enfureceu-se contra Raquel”), que dão conta da reacção de Jacob às preces da mulher que queria ter descendência. Estas palavras foram comentadas da seguinte forma: "Debent uiri immoderata uxorum desideria arguere et temperare.", isto é: "Os homens devem censurar e moderar os desejos sem medida das esposas". Azambuja tenta desculpabilizar a atitude pouco compreensiva de Jacob, responsabilizando moralmente a mulher. Mas o que aqui importa reter não é o conteúdo dos comentários, ditados pelo tempo em que foram redigidos, antes a sua dupla natureza, literal e moral.

Passemos agora ao último ponto da carta. Depois de elogiada a qualidade dos extensos comentários de Azambuja, Resende justifica o teor das suas palavras prefaciais. Elas destinam-se a testemunhar, perante o Cardeal, o valor do homenageado. Assiste-se então a um sub-reptício auto-elogio, quando o próprio Resende sublinha a magnanimidade de quem é capaz de reconhecer no outro o mérito que lhe é devido. Este tópico tornara-se numa espécie de leitmotiv das preocupações de Resende, pois muitas vezes se sentira esbulhado do reconhecimento a que tinha direito. Por isso não deixava de criticar aqueles que dificilmente valorizavam o trabalho dos outros, como deixou dito na carta De aera Hispanorum, de 1551, ou, mais tarde, na Carta a Bartolomeu de Quevedo, de $1567 .{ }^{25}$

E aqui chegamos ao cerne desta carta. De facto, prefaciar uma obra sempre foi, para o prefaciador, uma das formas de se fazer lembrado, de afirmar a sua consonância com o pensamento ortodoxo e de revelar a sua personalidade. Enfim, de se mostrar, eloquentemente, perante o poder.

\footnotetext{
24 "Não apenas para não o matarem, mas também para não o ferirem. Que sinal seria este, o texto não o explica, nem há conjectura que possa levar ao seu conhecimento. Além do mais, não é de bom grado que forjo histórias nos textos sagrados."

${ }^{25}$ Veja-se, a este título, Virgínia Soares Pereira (1987-1988), maxime pp. 211-216.
} 


\section{Texto latino e tradução}

\section{Nota prévia}

O texto que serviu de base à presente edição da carta de Resende é o que consta do volume intitulado: Reuerendi Patris Fratris Hieronymi Ab Oleastro Lusitani, Praedicatorii Ordinis, ac Sacrae Theologiae Professoris, atque haereticae prauitatis apud Inclytam Olyssiponem Inquisitoris Commentaria in Mosi Pentateuchum, iuxta M. Sanctis Pagnini Lucensis eiusdem ordinis interpretationem: quibus Hebraica ueritas exactissime explicatur: \& quae ad morum compositionem aptari possunt: ex ipsius literae penetralibus seorsum annectuntur. Opus sane, \& doctis, \& indoctis usui futurum. Olyssipone apud Iohannem Barrerium Regium Typographum. Anno a nato Seruatore nostro Iesu Christo M.D.L.VI. ${ }^{26}$

Note-se que o frontispício do volume, apesar de abarcar toda a obra (os cinco livros do Pentateuco), regista um impressor (João Barreira) e uma data (1556) que são válidos apenas para os Commentaria in Genesim, porquanto os restantes quatro livros tiveram edições em separado. São eles: Commentaria in Exodum /.../. Olyssiponi (sic), Ex officina Ioannis Blauij Coloniensis. M.D.LVII; Commentaria in Leuiticum /.../. Olisipone, Apud Ioannem Blauium, typographum regium. M.D.LVII; Commentaria in Librum Numerorum /.../. Olyssipone, Ex officina Ioannis Blauij Coloniensis. M.D.LVII; Commentaria in Librum Deuteronomii /.../. Olissipone, Exofficina (sic) Ioannis Blauij Coloniensis. 1558. M.D.LVIII. ${ }^{27}$

O exemplar desta obra que consultei encontra-se na Biblioteca Pública e Distrital de Braga (Cota Res. $676 \mathrm{~V}$ ) e é proveniente do Convento de Viana. ${ }^{28} \mathrm{~A}$ título

\footnotetext{
${ }^{26}$ Apenas os três primeiros livros têm cartas prefatórias, a primeira de Jerónimo de Azambuja, a segunda de Jerónimo de Brito e a terceira de André de Resende. Jerónimo de Azambuja é ainda autor de uma carta nuncupatória ao Cardeal D. Henrique e, a iniciar os Comentários ao Êxodo, surge uma carta elogiosa de Jerónimo Osório a Azambuja.

${ }^{27}$ Curiosamente, no verso do fólio 69, no final do Deuteronómio, vem escrito o seguinte: Expliciunt Comentaria (sic) magistri Hieronimi ab Oleastro Lusitani ordinis praedicatorum quos. 28. die mensis Maii anni. 1557 Vlisipone absoluit. Mais curioso é que o volume do Deuteronómio ostenta na folha de rosto a data de M. D. LVIII.

${ }^{28}$ Conforme se lê na folha de rosto desta edição quinhentista, em nota exarada em letra manuscrita, o exemplar é proveniente do Convento de Nossa Senhora do Carmo de Viana.
} 
informativo, diga-se que nesta valiosa Biblioteca de Braga existem exemplares de várias edições quinhentistas da obra de Azambuja. ${ }^{29}$ Segundo M. Augusto Rodrigues, alguns dos exemplares dos Commentaria in Pentateuchum foram expurgados pela censura inquisitorial. Dos exemplares que compulsei nem todos foram vítima de rasuras. ${ }^{30}$

O texto que se segue tem como base o da primeira edição (Lisboa, 1557). Feita a sua colação com a edição de Antuérpia, de 1568, e a de Lião, de 1588, não se registaram divergências textuais, pelo que não há necessidade de apresentar o aparato crítico. Introduziram-se, no entanto, algumas alterações, que respeitam as normas de modernização em vigor na edição de textos antigos. A saber:

O símbolo \& foi substituído por et; o grupo $-i j$ foi transcrito $-i i$; as vogais encimadas por um til foram transcritas com $-m$ final, como: $-\tilde{a}>-a m$; os grupos $-o e-\mathrm{e}$ -ae- foram registados como - e-; desfizeram-se abreviaturas, como: iterumq:, que se transcreveu iterumque.

A fim de facilitar a leitura da carta, introduziram-se parágrafos inexistentes no texto de base.

\footnotetext{
${ }^{29}$ Existem na Biblioteca Pública de Braga exemplares das seguintes edições quinhentistas de Azambuja: Commentaria in Mosi Pentateuchum, Olyssipone apud Iohannem Barrerium Regium Typographum, 1556 (Cota: Res. 676 V); Opera. Antuerpiae, In aedibus Viduae \& Haeredum Ioannis Stelsij. M.D.LXVIII (Cota: 2995 V.); Commentaria in Pentateuchum Mosi, Lugduni, Apud Petrum Landry, 1588 (Cota: R. 2140 P.); Opera. Antuerpiae, João Stelsii, 1569 (Cota: R. 1686 P.). Já do séc. XVII existem os In Isaiam prophetam Commentarii. Paris, Sebastião Cramoisy, 1622 (Cota: R. 1924 P.).

${ }^{30}$ Foram vistas as primeiras três edições referidas, verificando-se que a carta prefatória de Azambuja ao leitor foi rasurada no exemplar com a cota 2140 P. As rasuras incidem em especial no passo em que Azambuja explica a sua preferência pela tradução de Sanctes Pagnino e não pela Vulgata. Este exemplar procede "Da Communidade de N. S do Populo" (pertence ms.) e, em nota manuscrita da folha de rosto exara-se: Expurgatus. Por isso M. Augusto Rodrigues (1979: 191), salientando a importância do prefácio azambujano ao Pentateuco, afirma: "pensamos tecer-lhe alguns comentários à medida que transcrevemos as partes mais significativas, pois ele foi riscado de muitos exemplares pela censura inquisitorial." A carta de Resende não foi objecto de qualquer censura.
} 
Diui Emmanuelis Lusitaniae Regis,

Pii, Felicis, Inuicti filio, D. Henrico,

S. R. E. tituli Sanctorum quatuor coronatorum presbytero Cardinali, ac primo Eborensis ecclesiae Archiepiscopo,

Domino suo,

L. Andr. Resendius, indignus

sacrae theologiae professor

S. P. D.

Adcitus a te Olisiponem, Princeps sacratissime, et a meis studiis aliquantisper feriatus, dum domo absum, et ea quorum gratia me aduocaras perficio, soleo conuenire interdum religiosum ac bene doctum uirum F. Hieronymum Oleastrensem, sacrarum literarum ex illustri Diui Dominici instituto professorem, adlectum per te in hac Olisiponensi dioecesi ad inquirendum de haereticis, et in tenenda religione factiosis. Quod tametsi libenter facio, et propter uiri non uulgarem eruditionem, et quia olim a prima fere adolescentia in coenobiali conuersatione studia coniunxeramus, ob id tamen libentius, quod dignum eum ipse iudicasti, quuius fidei prouinciam non minus magnam quam periculosam, et summa morum ac religionis integritate indigentem, delegares.

Interea obruente nos Diui Ioannis III, fratris Germani tui, regis autem nostri ${ }^{31}$ et, ut uere dicam, patriae parentis, interitu, ac dum iusta non persoluuntur insequuto iustitio, quum tum ex publica maestitia, tum uero ex tua, animo nescio dissolutione magis, an destituto, ad illum uenissem, legendos mihi dedit suos in Genesin et Exodum commentarios, non longos illos quidem, sed quantum ad rem attinet longe copiosissimos. Quos cum ego, partim ut languenti animo sacrarum literarum lectione subuenirem, quibus et professionis instituto, et mentis propensione, quasi obaeratum me

\footnotetext{
${ }^{31}$ Note-se que também no poema Conquestio à morte de D. João III, editado no mesmo ano, Resende afirma como D. João era, mais do que rei, "pai da pátria": (...) qui patriae, potius quam rex, pater atque magister / iure bono dicendus erat (vv. 58-59).
} 
A D. Henrique, filho de D. Manuel, rei de Portugal,

Pio, Feliz, Invicto, Cardeal da Santa Igreja Romana,

Presbítero do Título dos Quatro Santos Coroados, e primeiro Arcebispo da Igreja de Évora,

seu Senhor,

L. André de Resende, humilde Professor de Teologia Sacra, envia muitas saudações.

Chamado por ti a Lisboa, Sacratíssimo Príncipe, e estando um tanto liberto dos meus estudos, por me encontrar ausente de casa, a dar cumprimento às incumbências que motivaram a tua convocação, tenho o hábito, de vez em quando, de me encontrar com Fr. Jerónimo de Oleastro, varão de grande religiosidade e cultura, professor de Letras Sagradas do ilustre instituto de S. Domingos, por ti nomeado para o exercício das funções de inquisidor dos heréticos e dos que renegam da religião, nesta diocese de Lisboa. ${ }^{32}$ Faço-o, sem dúvida, de bom grado, não apenas atendendo à invulgar erudição desse homem, mas também porque em tempos, praticamente desde os inícios da adolescência, compartilhámos os estudos na conversação cenobial, mas faço-o ainda mais gratamente pelo facto de tu mesmo o teres julgado digno de nele delegares o encargo da fé, tão importante quanto perigoso e necessitado da maior integridade de costumes e religiosidade.

Entretanto, neste momento em que se abate sobre nós a morte de D. João III, teu irmão verdadeiro, mas também rei nosso e, em boa verdade, pai da pátria, e enquanto não se realizam os seus funerais, passado o período do luto público, fui visitá-lo - de alma combalida, ou por motivo da tristeza pública, ou verdadeiramente da tua, não sei se mais afectado pela sua morte, se pelo desamparo - e ele deu-me a ler os seus Comentários ao Génesis e ao Êxodo, não extensos, de facto, mas, no que ao assunto diz respeito, de longe mais bem extensos. ${ }^{33}$ Ora, tendo-os eu lido, em parte para acorrer em auxílio ao meu ânimo languente mediante a leitura das Sagradas Escrituras -

\footnotetext{
${ }^{32}$ Recorde-se que Jerónimo de Azambuja era inquisidor em Lisboa desde 1555.

${ }^{33}$ É estranho que Resende se refira deste modo aos Comentários de Azambuja, se se atender a que, quando prefaciou o Levítico, já tinham saído (e ele tinha visto) os Comentários ao Génesis (que se estendem por 316 páginas), ao Êxodo (com 96 fólios) e ao próprio Levítico (com 67 fólios), para não falar dos Comentários aos Números (86 fólios) e ao Deuteronómio (67 fólios).
} 
sentiebam, partim ut adultae iam aestatis caloribus intra parietes facilius me absque taedio continerem, attente et cum delectu semel iterumque legissem, immane dictu quam placuerint, quam probauerim, quam amauerim, quam studiosis omnibus ex Hebraicae linguae salebris germanum literae et contextus sensum eruere ${ }^{34}$ cupientibus necessarios existimarim.

Vt de me ipse loquar, ex non paucis equidem obscurorum locorum difficultatibus, quasi oborta insperato luce tandem euasi, et ab aliquot qui me diu torserant nodis sum extricatus. ${ }^{35}$ Imputent hoc imbecillitati qui uelint, et ingenii mei quam et ipse fateor tenuitati, et quanto libeat supercilio ac fastu imputent, modo, ut de multis uel unum hoc adducam, ex trigesimi Geneseos capitis posteriore parte, in qua de Iacob cum Laban conuentione et patriarchae astu agitur, sine linguarum praesidio, si possunt, sese expediant. Summa haec est. Ego me hisce commentariis legendis profecisse confirmo, ac alios itidem profecturos certo polliceor, eos praecipue qui saltem mediocrem linguae sanctae peritiam habuerint. ${ }^{36}$ Id tuae Celsitudini, Princeps sacratissime, testatum propterea uolui, quod noster ipse Hieronymus eos tuos tibi iure dicauit. Simul, quia candoris maxime ingenui est, laboribus alienis, si per illos profeceris, gratiam habere, si non profeceris, neque etiam detrahere. Vale, Olisipone Idibus Iulij. M.D.LVII.

\footnotetext{
${ }^{34}$ Confronte-se com o que Azambuja escreve na pág. 167 do seu Commentarius ao Génesis, 49-1: Elaborauimus ergo huius capitis germanum sensum: ex his quae praediximus et ex significatione propria uerborum, quoad fieri poterit, obstrusum sensum eruere, (...) - citado de A. A. Marques Martins, 1966, p. 142-143. Na pág. 179 de Quorundam Locorum, o exegeta refere-se à importância do conhecimento do contextus para um correcto entendimento da Sagrada Escritura: Dico enim ibidem litterae genuinum sensum ex contextu uenandum: cum uerba quae praecedunt, nullo pacto debeant uirgini accomodari, cum non sit filia uaga, aut rebellis, qualis ibi dicitur sinagoga: non puto locum ad litteram de ea loqui. (cit. de A.A. Martins Marques (1966: 140). Comentando o passo Et ait Leah, Azambuja escreve: In exercitum, id est, tantam filiorum copiam habeo, quod possent exercitum constituere. Et re uera iste est germanus literae sensus (...).

${ }^{35}$ Como se comprova com o texto transcrito na nota anterior, e como se deduz do seu prefácio, também Azambuja confessa a dificuldade que sentiu em interpretar muitos dos passos, mas acrescenta que obteve progressos, pois com esforço conseguiu descobrir certos sentidos que antes the eram inteiramente obscuros.

${ }^{36}$ Azambuja confia igualmente em que a sua obra será de grande utilidade para os outros. A afirmação, recorrente, vem exarada logo na folha de rosto, ao dizer: Opus sane et doctis, et indoctis usui futurum.
} 
relativamente às quais me sentia como que penhorado, não apenas em conformidade com o meu ofício, mas também por inclinação de espírito -, em parte para mais facilmente me manter em casa e sem tédio, pois iam já avançados o verão e a canícula, - tendo-os eu lido uma e várias vezes com atenção e com deleite, é-me impossível exprimir quanto me agradaram, quanto os aprovei, quanto os apreciei, quanto os considerei - dadas as dificuldades da língua hebraica - necessários a todos os estudiosos interessados em descobrir o verdadeiro sentido da letra e do contexto.

Para falar de mim próprio, vi-me livre, finalmente, de não poucas dificuldades respeitantes a passos obscuros, como se de repente me surgisse uma luz, e deslindaramse-me alguns nós que durante muito tempo me tinham atormentado. Que quem o queira impute o facto à minha debilidade e à fraqueza - que eu próprio reconheço - do meu talento, e a seu bel-prazer, de sobrolho carregado e com orgulho o impute, se for capaz de por si só, sem o auxílio de intérpretes, resolver, para citar um só exemplo de entre muitos, o passo Génesis 30, segunda parte, na qual se fala do encontro de Jacob com Labão e da astúcia do Patriarca. Em suma. Pela minha parte, atesto que me foi muito proveitosa a leitura destes Comentários, e garanto, sem a mínima dúvida, que aproveitará de igual modo a outros, especialmente àqueles que tenham um domínio pelo menos mediano da língua sagrada. Por isso quis dar disto testemunho perante Vossa Alteza, Sacratíssimo Príncipe, atendendo ao facto de o nosso próprio Jerónimo tos ter dedicado de pleno direito. Decidi fazê-lo, também, porque é próprio de um carácter particularmente cândido ficar reconhecido aos trabalhos de outrem, se graças a ele se alcançar proveito, e também, se acaso se não alcançar, também não os denegrir.

Adeus. Nos Idos de Julho de 1557. 


\section{Bibliografia consultada}

Cerejeira, M. Gonçalves (1974-1975), O Renascimento em Portugal: I - Clenardo e a sociedade portuguesa; II - Clenardo: o Humanismo e a Reforma, Coimbra, Coimbra Editora Limitada.

Ferreira, F. Leitão (1910), "Notícias da vida de André de Resende", publicadas, anotadas e aditadas por A. Braancamp Freire, Arquivo Histórico Português VIII, pp. 338-366.

Ferreira, F. Leitão (1914), "Notícias da vida de André de Resende", publicadas, anotadas e aditadas por A. Braancamp Freire, Arquivo Histórico Português IX, pp. 177-285.

Marques, A. A. Martins (1966), "A obra exegética de Fr. Jerónimo de Azambuja. Breve comparação dos comentários”, Theologica, Braga, 1, pp. 123-150.

Marques, A. A. Martins (1964-1966), "Frei Jerónimo de Azambuja e a sua actividade inquisitorial”, Lusitania Sacra VII, pp. 193-216.

Matos, Luís de (1976), "Ebora Humanistica”, A Cidade de Évora, 59, pp. 5-21.

Pereira, Isaías da Rosa (1991-1992), “Os sermões de André de Resende nos sínodos de Évora de 1534 e de 1565 e as falas de Francisco de Melo no sínodo de 1534”, Humanitas, 43-44, pp. 185201.

Pereira, Isaías da Rosa (1971), "Sínodo Diocesano de Évora de 1534”, Anais da Academia Portuguesa de História, $2^{\mathrm{a}}$ série, vol. 20, pp. 171-232.

Pereira, Virgínia Soares (1987-1988), "Uma carta de André de Resende reconstituída", Humanitas 39-40, pp. 211-232.

Pinho, Sebastião Tavares de (2006), Humanismo em Portugal, Estudos I, Lisboa, Imprensa Nacional-Casa da Moeda, 153-182.

Rego, Raul (1982), Os Índices expurgatórios e a cultura portuguesa, Lisboa, Biblioteca Breve.

Resende, André de (2000), “Aegidius Scallabitanus”- Um diálogo sobre Fr. Gil de Santarém. Estudo introdutório, edição crítica, tradução e notas de Virgínia Soares Pereira. Lisboa, Fundação Calouste Gulbenkian, Fundação para a Ciência e Tecnologia.

Resende, André de (1981), Vincentius leuita et martyr. Reproduction en fac-similé de l'édition de Luís Rodrigues, Lisbonne, 1545. Introduction para José V. de Pina Martins, Braga, Barbosa \& Xavier.

Rodrigues, Manuel Augusto (1973), "O estudo do hebraico em Portugal no século XVI", $O$ Instituto, Coimbra, 136, pp. 1-46.

Rodrigues, Manuel Augusto (1974), "A cátedra de Sagrada Escritura na Universidade de Coimbra", Biblos, Coimbra, 50, pp. 1-612.

Rodrigues, Manuel Augusto (1977), "Alguns aspectos da obra exegética de Fr. Jerónimo de Azambuja (Oleastro), O.P.”, Revista Portuguesa de História, Coimbra, 17, pp. 25-36.

Rodrigues, Manuel Augusto (1979), “A obra exegética de Fr. Jerónimo de Azambuja”, Biblos, Coimbra, 55, pp. 183-195.

Rodrigues, Manuel Augusto (1984), "Les études hébraïques à l'Université de Coimbra (XVIe siècle)", L'Humanisme portugais et l'Europe - Actes du XXI Colloque International d'Études Humanistes, Tours, 3-13 Juillet 1978, Paris, Gulbenkian, pp. 111-160. 